Intecoms: Journal of Information Technology and Computer Science

Volume 2 Nomor 1, Juni 2019

e-ISSN : 2614-1574

p-ISSN : 2621-3249

DOI : https://doi.org/10.31539/intecoms.v2i1.594

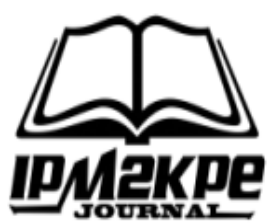

\title{
UPAYA PENINGKATAN KOMPETENSI GURU DALAM MENYUSUN SILABUS DAN RPP MELALUI SUPERVISI AKADEMIK BERBASIS IT YANG BERKELANJUTAN
}

\section{COMPETENCE ENHANCEMENT EFFORTS IN TEACHING AND TRAINING THROUGH SUSTAINABLE IT-BASED ACADEMIC SUPERVISION}

\author{
Rizka Khaira \\ SMA Negeri 2 Lubuk Sikaping \\ rizkakhaira@gmail.com
}

\begin{abstract}
Every process must always include three main activities, namely planning, implementation and evaluation. Similarly, what happens with the teaching and learning process in schools? A teacher is required to carry out planning, implementation and evaluation of learning. The learning planning process that must be carried out by a teacher includes the following main activities: 1) Making an annual program; 2) Making syllabus; 3) Making semester programs; 4) Make a plan for implementing learning; 5) And make a repeat / evaluation program. Of the five elements mentioned above, the syllabus and lesson plan are the minimum preparation for a teacher when they want to teach. Based on the results of the first semester analysis in the 2017/2018 school year at Lubuk Sikaping 2 High School, the problem arises the low ability of teachers to make learning planning, especially the preparation of syllabus and lesson plans in accordance with the 2013 curriculum. Seeing the extent to which the principal's academic supervision can improve teacher competence in the preparation of syllabus and Learning Implementation Plans.
\end{abstract}

Keywords: Teachers' Competency, Academis Supervision, Silabus

\begin{abstract}
ABSTRAK
Setiap proses pasti selalu meliputi tiga kegaiatan utama yakni perencanaan, pelaksanaan dan evaluasi Demikian pula yang terjadi dengan proses belajar mengajar di sekolah. Seorang guru diharuskan melakukan perencanaan, pelaksanaan dan evaluasi pembelajaran. Proses perencanaan pembelajaran yang harus dilakukan oleh seorang guru meliputi kegiatan utama sebagai berikut : 1) Membuat program tahunan; 2) Membuat silabus; 3) Membuat program semester; 4) Membuat rencana pelaksanaan pembelajaran; 5) Dan membuat program ulangan/evaluasi. Dari kelima unsur tersebut di atas, silabus dan RPP merupakan persiapan paling minimal seorang guru ketika hendak mengajar. Berdasar kepada hasil analisa semester pertama pada tahun pelajaran 2017/2018 di SMA Negeri 2 Lubuk Sikaping, muncul permasalahan rendahnya kemampuan guru membuat perencanaan pembelajaran khususnya penyusunan silabus dan RPP yang sesuai dengan kurikulum 2013. Untuk meneliti lemahnya kinerja guru dalam hal tersebut, dilakukanlah penelitian untuk melihat sejauhmana langkah supervisi akademik kepala sekolah dapat meningkatkan kompetensi guru dalam penyusunan silabus dan Rencana Pelaksanaan Pembelajaran.
\end{abstract}

Kata Kunci: Kompetensi Guru, Supervisi Akademik, Silabus

\section{PENDAHULUAN}

Dalam strategi pembelajaran terkandung tiga hal pokok yakni perencanaan, pelaksanaan dan evaluasi. Perencanaan program berfungsi untuk memberikan arah pelaksanaan pembelajaran sehingga menjadi terarah dan efisien. Salah satu bagian dari perencanaan pembelajaran yang sangat penting dibuat oleh guru sebagai pengarah pembelajaran adalah silabus dan Rencana Pelaksanaan Pembelajaran (RPP). 
Hasil pengamatan di tahun pelajaran 2017/2018 di SMA Negeri 2 Lubuk Sikaping, didapatkan data sebagai berikut: 1) Hanya 60\% guru yang menyusun silabus dan RPP; 2) Secara kualitas, silabus dan RPP yang baik baru mencapai angka $40 \%$ dari silabus dan RPP yang dibuat oleh guru.

Guru yang profesional adalah mereka yang memiliki kemampuan profesional dengan berbagai kapasitasnya sebagai pendidik. Studi yang dilakukan oleh Ace Suryani menunjukkan bahwa Guru yang bermutu dapat diukur dengan lima indikator, yaitu:

Kemampuan profesional (professional capacity) sebagaimana terukur dari ijazah, jenjang pendidikan, jabatan dan golongan, serta pelatihan.

Upaya profesional (professional efforts) sebagaimana terukur dari kegiatan mengajar, pengabdian dan penelitian.

Waktu yang dicurahkan untuk kegiatan profesional (teacher's time) sebagaimana terukur dari masa jabatan, pengalaman mengajar serta lainnya.

Kesesuaian antara keahlian dan pekerjaannya (link and match) sebagaimana terukur dari mata pelajaran yang diampu, apakah telah sesuai dengan spesialisasinya atau tidak, serta

Tingkat kesejahteraan (prosperiousity) sebagaimana terukur dari upah, honor atau penghasilan rutinnya. Tingkat kesejahteraan yang rendah bisa mendorong seorang pendidik untuk melakukan kerja sambilan, dan bilamana kerja sambilan ini sukses, bisa jadi profesi mengajarnya berubah menjadi sambilan.

Majid (2005) menjelaskan kompetensi yang dimiliki oleh setiap guru akan menunjukkan kualitas guru dalam mengajar. Kompetensi tersebut akan terwujud dalam bentuk penguasaan pengetahuan dan profesional dalam menjalankan fungsinya sebagai guru. Diyakini Robotham (1996) kompetensi yang diperlukan oleh seorang guru tersebut dapat diperoleh baik melalui pendidikan formal maupun pengalaman.

Sejalan dengan itu Finch \& Crunkilton (1979) sebagaimana dikutip oleh Mulyasa (2003) mengartikan kompetensi sebagai penguasaan terhadap suatu tugas, keterampilan, sikap, dan apresiasi yang diperlukan untuk menunjang keberhasilan. Sofo (1999:123) mengemukakan " $A$ competency is composed of skill, knowledge, and attitude, but in particular the consistent applications of those skill, knowledge, and attitude to the standard of performance required in employment".

Dengan kata lain kompetensi tidak hanya mengandung pengetahuan, keterampilan dan sikap, namun yang penting adalah penerapan dari pengetahuan, keterampilan, dan sikap yang diperlukan tersebut dalam pekerjaan. Robbins (2001) menyebut kompetensi sebagai ability, yaitu kapasitas seseorang individu untuk mengerjakan berbagai tugas dalam suatu pekerjaan.

\section{METODE PENELITIAN}

Penelitian ini dilakukan dengan metode penelitian tindakan kelas yang berlangsung selama 2 siklus. Masingmasing siklus terdiri dari tahapan perencanaan, pelaksanaan, observasi dan refleksi. Metode penelitian yang dilakukan peneliti adalah dengan melaksanakan supervisi akademik yang meliputi supervisi tradisional dan supervisi klinis yang secara rinci dapat diuraikan sebagai berikut :

Perencanaan awal, langkah awal terdiri dari beberapa kegiatan, yakni: 
Identifikasi masalah, Pengajuan proposal, Mempersiapkan instrument.

Siklus pertama yang terdiri dari perencanaan, pelaksanaan, observasi, refleksi. Siklus kedua terdiri dari perencanaan, pelaksanaan, observasi dan refleksi

Lokasi penelitian adalah di SMA Negeri 2 Lubuk Sikaping Kabupaten Pasaman Sumatera Barat. Waktu pelaksanaan direncanakan selama satu setengah bulan mulai tanggal 1 Maret s.d. 20 April 2018.

\section{HASIL DAN PEMBAHASAN \\ Kompetensi Guru Sebelum Kegiatan Penelitian}

1. Kuantitas silabus dan RPP tahun pelajaran 2017/2018

Pada akhir tahun pelajaran 2017/2018, peneliti mencatat guru yang menyetorkan perangkat pembelajaran untuk ditandatangani. Hasil perhitungan perangkat pembelajaran yang dikumpulkan dapat dilihat pada tabel berikut :

Lebih jelasnya, presentase jumlah guru yang mengumpulkan perangkat pembelajaran sebelum kegiatan adalah:

Tabel. 1 Rekapitulasi Guru yang Menyetorkan Perangkat Pembelajaran

\begin{tabular}{llccc}
\hline $\mathrm{N}$ & Komponen & $\begin{array}{c}\text { Jumla } \\
\mathrm{h}\end{array}$ & $\begin{array}{c}\text { Yang } \\
\text { Mengum } \\
\text { pulkan } \\
\text { uhnya }\end{array}$ & $\begin{array}{c}\text { \%ang } \\
\text { Meng } \\
\text { umpu } \\
\text { lkan }\end{array}$ \\
\hline 1 & $\begin{array}{l}\text { Standarisi } \\
\text { mata } \\
\text { pelajaran }\end{array}$ & 45 & 27 & 60 \\
2 & $\begin{array}{l}\text { Kalender } \\
\text { pendidikan }\end{array}$ & 45 & 45 & 100 \\
3 & $\begin{array}{l}\text { Program } \\
\text { tahunan }\end{array}$ & 45 & 27 & 60 \\
4 & $\begin{array}{l}\text { Program } \\
\text { semester }\end{array}$ & 45 & 27 & 60 \\
5 & $\begin{array}{l}\text { KKM } \\
\text { Analisis } \\
\text { tujuan }\end{array}$ & 45 & 27 & 60 \\
mata & 45 & 19 & 42 \\
\hline
\end{tabular}

\begin{tabular}{|c|c|c|c|c|}
\hline & pelajaran & & & \\
\hline 7 & $\begin{array}{l}\text { Analisis } \\
\text { materi } \\
\text { mata } \\
\text { pelajaran }\end{array}$ & 45 & 19 & 42 \\
\hline 8 & $\begin{array}{l}\text { Analisis } \\
\text { pemetaan } \\
\text { SK/KD }\end{array}$ & 45 & 19 & 42 \\
\hline 9 & Silabus & 45 & 27 & 60 \\
\hline 10 & RPP & 45 & 27 & 60 \\
\hline 11 & $\begin{array}{l}\text { Agenda } \\
\text { kegiatan } \\
\text { harian }\end{array}$ & 45 & 19 & 42 \\
\hline 12 & $\begin{array}{l}\text { Pelaksanaa } \\
\text { n prog } \\
\text { semester }\end{array}$ & 45 & 19 & 42 \\
\hline 13 & $\begin{array}{l}\text { Daftar } \\
\text { hadir siswa }\end{array}$ & 45 & 45 & 100 \\
\hline 14 & Daftar nilai & 45 & 45 & 100 \\
\hline 15 & $\begin{array}{l}\text { Analisis } \\
\text { hasil UH }\end{array}$ & 45 & 19 & 42 \\
\hline 16 & $\begin{array}{l}\text { Analisis } \\
\text { hasil UTS }\end{array}$ & 45 & 45 & 100 \\
\hline 17 & $\begin{array}{l}\text { Analisis } \\
\text { butir soal }\end{array}$ & 45 & 27 & 60 \\
\hline 18 & Bank soal & 45 & 27 & 60 \\
\hline 19 & $\begin{array}{l}\text { Program } \\
\text { perbaikan } \\
\text { pengayaan }\end{array}$ & 45 & 19 & 42 \\
\hline 20 & $\begin{array}{l}\text { Laporan } \\
\text { hasil } \\
\text { perbaikan }\end{array}$ & 45 & 19 & 42 \\
\hline \multicolumn{2}{|c|}{ JUMLAH } & 900 & 548 & 1.216 \\
\hline
\end{tabular}

2. Kualitas silabus dan RPP guru tahun pelajaran 2017/2018

Tabel. 2 Daftar Nilai Kualitas Silabus dan RPP Tahun Pelajaran 2017

\begin{tabular}{|c|c|c|c|c|}
\hline No & Nama Guru & Silabus & RPP & $\begin{array}{l}\text { Rata- } \\
\text { rata }\end{array}$ \\
\hline 1 & $\begin{array}{l}\text { Dra. Gusti } \\
\text { Mawarti }\end{array}$ & 75 & 60 & 68 \\
\hline 2 & Dra Amrida & 75 & 69 & 72 \\
\hline 3 & $\begin{array}{l}\text { Syafrizal, } \\
\text { S.Pd }\end{array}$ & 61 & 70 & 66 \\
\hline 4 & $\begin{array}{l}\text { Abdul } \\
\text { Rahman, } \\
\text { S.Pdi }\end{array}$ & 61 & 63 & 62 \\
\hline 5 & $\begin{array}{l}\text { Mirhamah, } \\
\text { S.Pd }\end{array}$ & 64 & 75 & 70 \\
\hline 6 & $\begin{array}{l}\text { Yulfitra } \\
\text { Susilawati, } \\
\text { S.Pd }\end{array}$ & 64 & 60 & 62 \\
\hline 7 & Desi & 64 & 60 & 62 \\
\hline
\end{tabular}




\begin{tabular}{|c|c|c|c|c|}
\hline & $\begin{array}{l}\text { Herawati, } \\
\text { S.Pd }\end{array}$ & & & \\
\hline 8 & Farida, S.Pd & 61 & 60 & 61 \\
\hline 9 & $\begin{array}{l}\text { Dince Putri } \\
\text { Juita, S.Si }\end{array}$ & 75 & 81 & 78 \\
\hline 10 & $\begin{array}{l}\text { Zuraydah } \\
\text { Koto, S.Pd }\end{array}$ & 75 & 70 & 73 \\
\hline 11 & $\begin{array}{l}\text { Marlis } \\
\text { Suarni, S.Pd }\end{array}$ & 80 & 85 & 83 \\
\hline 12 & $\begin{array}{l}\text { Syafni } \\
\text { Mailirianti, } \\
\text { S.Pd }\end{array}$ & 75 & 80 & 78 \\
\hline 13 & $\begin{array}{l}\text { Yulmainis, } \\
\text { S.E }\end{array}$ & 75 & 75 & 75 \\
\hline 14 & $\begin{array}{l}\text { Resti } \\
\text { Hidayati } \\
\text { Putri, S.Pd }\end{array}$ & 77 & 77 & 77 \\
\hline 15 & $\begin{array}{l}\text { Yosedilla } \\
\text { Susra, S.Pd }\end{array}$ & 65 & 70 & 68 \\
\hline 16 & $\begin{array}{l}\text { Nova } \\
\text { Gusnida, } \\
\text { S.Pd }\end{array}$ & 75 & 75 & 75 \\
\hline 17 & $\begin{array}{l}\text { Shinta Titia } \\
\text { Sari, S.Kom. } \\
\text { M.M.Pd }\end{array}$ & 75 & 75 & 75 \\
\hline 18 & $\begin{array}{l}\text { Erlindawati, } \\
\text { S.Pd }\end{array}$ & 75 & 75 & 75 \\
\hline 19 & $\begin{array}{l}\text { Fitri } \quad \text { Efri } \\
\text { Yanti, S. Pd.I }\end{array}$ & 70 & 70 & 70 \\
\hline 20 & $\begin{array}{l}\text { Yurnalis, } \\
\text { S.Pd.I }\end{array}$ & 70 & 68 & 69 \\
\hline 21 & $\begin{array}{l}\text { Irhamni, } \\
\text { S.Pd.I }\end{array}$ & 66 & 66 & 66 \\
\hline 22 & $\begin{array}{l}\text { Marlisa } \\
\text { Susanti, } \\
\text { S.Pd.I }\end{array}$ & 65 & 60 & 63 \\
\hline 23 & $\begin{array}{l}\text { Rahmad, } \\
\text { S.Pd }\end{array}$ & 70 & 70 & 70 \\
\hline 24 & $\begin{array}{l}\text { Feri Antoni, } \\
\text { S.Sn }\end{array}$ & 60 & 60 & 60 \\
\hline 25 & $\begin{array}{l}\text { Syafrinal, } \\
\text { S.Pd }\end{array}$ & 60 & 60 & 60 \\
\hline 26 & $\begin{array}{l}\text { Drs. } \\
\text { Indrawardi }\end{array}$ & 70 & 70 & 70 \\
\hline 27 & Masril, M.Pd & 80 & 80 & 80 \\
\hline 28 & $\begin{array}{l}\text { Oktaria Mega } \\
\text { Sari, S.Pd }\end{array}$ & 75 & 75 & 75 \\
\hline 29 & $\begin{array}{l}\text { Mimi Yantri, } \\
\text { S.Pd }\end{array}$ & 75 & 75 & 75 \\
\hline 30 & $\begin{array}{l}\text { Dra. Sriwiyati } \\
\text { Abbas }\end{array}$ & 80 & 80 & 80 \\
\hline 31 & $\begin{array}{l}\text { Sardayanti, } \\
\text { S.Pd }\end{array}$ & 70 & 70 & 70 \\
\hline 32 & $\begin{array}{l}\text { Fitri Yosa } \\
\text { Restia, S.Pd }\end{array}$ & 65 & 65 & 65 \\
\hline 33 & $\begin{array}{l}\text { Haslina, S.Pd, } \\
\text { M.M }\end{array}$ & 65 & 70 & 68 \\
\hline 34 & Ainul & 60 & 60 & 60 \\
\hline
\end{tabular}

\begin{tabular}{|c|c|c|c|c|}
\hline & $\begin{array}{l}\text { Mardiah, } \\
\text { S.Pd.I }\end{array}$ & & & \\
\hline 35 & $\begin{array}{l}\text { Dodi Albert, } \\
\text { S.Pd }\end{array}$ & 60 & 60 & 60 \\
\hline 36 & $\begin{array}{l}\text { Nina Noffita } \\
\text { Risma, S.Pd }\end{array}$ & 65 & 65 & 65 \\
\hline 37 & Sulastri, Sos & 70 & 75 & 73 \\
\hline 38 & $\begin{array}{l}\text { Rezky Maisa } \\
\text { Putra, S.Pd }\end{array}$ & 70 & 70 & 70 \\
\hline 39 & $\begin{array}{l}\text { Enny } \\
\text { Maryam, } \\
\text { M.Pd }\end{array}$ & 75 & 80 & 78 \\
\hline 40 & $\begin{array}{l}\text { Wasiatul } \\
\text { Ilmah, S.Pd }\end{array}$ & 65 & 60 & 63 \\
\hline 41 & $\begin{array}{l}\text { Wito } \\
\text { Gudman, } \\
\text { S.Pd }\end{array}$ & 60 & 60 & 60 \\
\hline 42 & Yuliarti, S.Pd & 75 & 75 & 75 \\
\hline 43 & $\begin{array}{l}\text { Widha } \\
\text { Sucharia } \\
\text { Pratami, S.Psi }\end{array}$ & 70 & 65 & 68 \\
\hline 44 & $\begin{array}{l}\text { Debi Dalsia, } \\
\text { S.Pd }\end{array}$ & 60 & 65 & 63 \\
\hline 45 & $\begin{array}{l}\text { Widya } \\
\text { Destiana, } \\
\text { S.Pd }\end{array}$ & 65 & 65 & 65 \\
\hline \multicolumn{2}{|c|}{ Nilai Tertinggi } & 80 & 85 & 83 \\
\hline \multicolumn{2}{|c|}{ Nilai Terendah } & 60 & 60 & 60 \\
\hline \multicolumn{2}{|c|}{ Rata-rata } & 69 & 69 & 69 \\
\hline \multicolumn{2}{|c|}{ Jumlah $<70$} & 20 & 20 & 22 \\
\hline \multicolumn{2}{|c|}{ Jumlah $>70$} & 25 & 25 & 23 \\
\hline \multicolumn{2}{|c|}{ Persentase $<70$} & 44 & 44 & 49 \\
\hline \multicolumn{5}{|c|}{$\begin{array}{l}\text { Sumber : Data penilaian silabus dan RPP SMA } \\
\text { Negeri Lubuk Sikaping } 2018\end{array}$} \\
\hline \multicolumn{5}{|c|}{$\begin{array}{l}\text { Kompetensi Guru dalam Menyusun } \\
\text { Silabus Setelah Siklus Ke -1 } \\
\text { Hasil analisis kualitas silabus dan } \\
\text { RPP tersebutdapat terlihat pada table } \\
\text { berikut: }\end{array}$} \\
\hline \multicolumn{5}{|c|}{$\begin{array}{c}\text { Tabel. } 3 \text { Rekapitulasi Penilaian Silabus dan } \\
\text { RPP Pada Siklus } 1\end{array}$} \\
\hline No & $\begin{array}{c}\text { Klasifikasi } \\
\text { Penilaian }\end{array}$ & $\begin{array}{l}\text { Rentang } \\
\text { Nilai }\end{array}$ & f & $\%$ \\
\hline $\mathrm{A}$ & SILABUS & & & \\
\hline 1 & $\begin{array}{l}\text { A : Baik } \\
\text { sekali }\end{array}$ & $86-100$ & 0 & 0 \\
\hline 2 & B : Baik & $71-85$ & 17 & 38 \\
\hline 3 & C: Cukup & $51-70$ & 28 & 62 \\
\hline 4 & D : Kurang & $0-50$ & 0 & 0 \\
\hline \multicolumn{4}{|c|}{ Jumlah } & 100 \\
\hline \multicolumn{4}{|c|}{ Presentase A dan B } & 38 \\
\hline $\mathrm{B}$ & RPP & & & \\
\hline 1 & A : Baik & $86-100$ & 0 & 0 \\
\hline
\end{tabular}




\begin{tabular}{|c|c|c|c|c|}
\hline & Seklai & & & \\
\hline 2 & B : Baik & $71-85$ & 15 & 33 \\
\hline 3 & C : Cukup & $51-70$ & 30 & 67 \\
\hline 4 & D : Kurang & $0-50$ & 0 & 0 \\
\hline \multicolumn{4}{|c|}{ Jumlah } & 100 \\
\hline \multicolumn{4}{|c|}{ Presentase A dan B } & 33 \\
\hline
\end{tabular}

\section{SIMPULAN}

Berdasarkan hasil penelitian ini, kami dapat menyimpulkan bahwa:

1. Supervisi akademik secara berkelanjutan terbukti secara ilmiah dapat meningkatkan kompetensi guru dalam menyusun silabus dan RPP di SMA Negeri 2 Lubuk Sikaping. Ini terbukti dengan meningkatnya jumlah silabus guru yang baik dari $31 \%$ menjadi $83 \%$ setelah supervisi akademik. Selain itu jumlah RPP yang berkualitas baik juga meningkat dari $31 \%$ menjadi $89 \%$;

2. Langkah-langkah mengakibatkan yang peningkatan kompetensi guru dalam menyusun silabus dan RPP tersebut meliputi langkah-langkah sebagai berikut: pengumuman rencana supervisi terhadap guru, pelaksanaan supervisi individual, dimana setiap guru diminta mempresentasikan silabus dan RPP nya kepada kepala sekolah, kemudian kepala sekolah memberikan masukan terhadap kekurangan silabus dan RPP guru, untuk mengecek originalitas silabus dan RPP yang disusun guru, kepala sekolah melakukan supervisi kelas. Hal ini dilakukan untuk menyesuaikan rencana yang dimuat dalam silabus dan RPP dengan penerapannya di kelas. Jika sesuai maka dapat dipastikan, kompetensi guru dalam menyusun silabus dan RPP tersebut benar (bukan jiplakan atau dibuatkan orang lain). Jika banyak ketidaksesuaian maka ada kemungkinan silabus dan RPP tersebut dibuatkan oleh orang lain;

3. Peningkatan kompetensi guru dalam menyusun silabus dan RPP yang baik meningkat sebesar 52\% dan 58\%.

\section{DAFTAR PUSTAKA}

Majid, A. (2005). Perencanaan Pembelajaran: Mengembangkan Standar Kompetensi Guru. Bandung: PT Remaja Rosdakarya.

Mulyasa, E. (2003). Kurikulum Berbasis Kompetensi: Konsep, Karakteristik, dan Implementasi. Bandung: PT Remaja Rosdakarya

Robbins, S. P. (2001). Organizational Behavior. New Jersey: Pearson Education International

Robotham, D. (1996). Competences: Measuring the Immeasurable, Management Development Review, 9(5), 25-29

Sofo, F. (1999). Human Resource Development, Perspective, Roles and Practice Choice. Business and Professional Publishing, Warriewood, NWS 